J Ocular Biol

November 2016 Vol.:4, Issue:1

(c) All rights are reserved by Brandt et al.

\title{
A Mouse Model of Multi-Drug Resistant Staphylococcus au- reus-induced Ocular Disease
}

\begin{abstract}
Keywords: Staphylococcus aureus; MRSA; Ocular disease; Bacterial keratitis; Mouse model

Abstract

Staphylococcus aureus infection of the cornea is a significant threat to vision. The percentage of bacterial isolates resistant to antibiotics is increasing as is the percentage of infections caused by methicillin resistant isolates. There is a critical need for additional therapeutic approaches and their development will require the use of animal models to test efficacy. Two mouse models of S. aureus keratitis have been described but only quantified stromal keratitis (corneal clouding and perforation). We have extended these models using the methicillin resistant S. aureus USA300 LAC strain and show that eyelid inflammation and swelling (blepharitis) and corneal neovascularization can be quantified. This expanded model should prove useful in assessing additional effects of antibacterial therapies and additiona pathological mechanisms involved in bacterial ocular infection.
\end{abstract}

\section{Abbreviations \\ MRSA: Methicillin Resistant Staphylococcus aureus; S. aureus: Staphylococcus aureus}

\section{Introduction}

Humans carry Staphylococcus aureus (S. aureus) in numerous body sites [1-3] and it is the most common cause of hospital and community-acquired infections worldwide [5-9]. Community associated methicillin-resistant $S$. aureus (MRSA) infections are estimated to cost $\$ 1.4$ to 13.8 billion annually [10]. Infection of the eye with $S$. aureus can also cause bacterial keratitis [11-13]. In the past 20 years, the number of ocular MRSA infections has increased worldwide [14-18]. One $S$. aureus strain, MRSA-USA300 (USA300), is common in community acquired infections $[19,20]$. Symptoms of bacterial keratitis include pain, redness, inflammation, opacity of the affected cornea, and ulceration [21]. Individuals who have undergone ocular surgery, who use contact lenses, and those who have had ocular viral infection or ocular trauma are more susceptible to bacterial keratitis [22-24].

Typically, bacterial keratitis is treated with topical antibiotics [25]. A key issue in bacterial keratitis treatment is that while bacteria rapidly proliferate prior to disease, by the onset of severe symptoms, the bacteria have stopped growing and may have formed an antibioticresistant biofilm. In addition to damage from the immune response, non-growing (stationary) phase $S$. aureus produces a number of toxins that contribute to corneal damage [26]. Prompt bactericidal therapy of asymptomatic infection is imperative, but is dependent on when the patient seeks help and the availability of appointments, so this is not always achievable. Many isolates of $S$. aureus are resistant to antibiotics with some strains being resistant to multiple antibiotics [27-32]. New approaches are needed to treat ocular infections caused

\section{Journal of Ocular Biology}

\author{
Nicole M. Broekema1, Inna V. Larsen², Erika S. \\ Naruzawa', Marcin Filutowicz ${ }^{1,3}$, Aaron W. Kolb², \\ Leandro B. C. Teixeira ${ }^{4}$ and Curtis R. Brandt ${ }^{2,5,6^{*}}$ \\ ${ }^{1}$ Amebagone, Inc.
}

${ }^{2}$ Department of Ophthalmology and Visual Sciences, School of Medicine and Public Health, University of Wisconsin-Madison, Wisconsin, USA

${ }^{3}$ Department of Bacteriology, University of Wisconsin-Madison, Wisconsin, USA

${ }^{4}$ Department of Pathobiological Sciences, School of Veterinary Medicine, University of Wisconsin-Madison, Wisconsin, USA

sDepartment of Medical Microbiology and Immunology, School of Medicine and Public Health, University of Wisconsin-Madison, Wisconsin, USA

${ }^{6}$ McPherson Eye Research Institute - University of Wisconsin-Madison, Wisconsin, USA

*Address for Correspondence

Curtis R. Brandt, Department of Ophthalmology and Visual Sciences, School of Medicine and Public Health, University of Wisconsin-Madison, 550 Bardeen, 1300 University Avenue, Madison, Wisconsin 53706, USA, Tel: 608-262-8054; Fax: 608-262-0479; E-mail: crbrandt@wisc.edu

Submission: 28 September, 2016

Accepted: 26 October, 2016

Published: 10 November, 2016

Copyright: $\odot 2016$ Broekema NM, et al. This is an open access article distributed under the Creative Commons Attribution License, which permits unrestricted use, distribution, and reproduction in any medium, provided the original work is properly cited.

by antibiotic-resistant $S$. aureus and other bacteria.

Previously, two models of $S$. aureus keratitis were described. Girgis developed a mouse model using S. aureus (strain 8325-4) and Zaidi et al. used the USA300 strain [33,34]. However, S. aureus 83254 is a laboratory strain that carries multiple mutations that may alter the virulence properties of this strain $[35,36]$. There is also conflicting data on whether this lab-adapted strain can form biofilms [37-40]. Furthermore, these previous studies only scored corneal damage due to stromal keratitis (clouding and perforation). Other pathological manifestations such as blepharitis and corneal neovascularization were not scored. Because other parameters of ocular pathology could be important endpoints in studies of disease mechanisms and evaluating new therapies, we adapted a mouse ocular disease scoring system that we have utilized for antiviral studies [41-48]. In this study, we assessed blepharitis, corneal neovascularization and stromal keratitis in USA300-infected, Ciprofloxacin-treated and untreated mice. This mouse model will be useful for further development and testing of ocular topical antimicrobials and studies on the mechanisms of pathogenesis.

\section{Methods}

\section{Bacteria}

The $S$. aureus USA300 LAC strain was cultured overnight at 37 ${ }^{\circ} \mathrm{C}$ with shaking at $225 \mathrm{rpm}$ in Tryptic Soy Broth. The culture was then centrifuged at $4000 \mathrm{rpm}$ for $10 \mathrm{~min}$, resuspended in $40 \mathrm{ml}$ of phosphate buffered saline (PBS), and centrifuged again at $4000 \mathrm{rpm}$ for $5 \mathrm{~min}$. The pellet was then resuspended in $1 \mathrm{ml}$ of PBS. Colony Forming Units (CFU) of the suspension were determined on SM/2 
agar plates (supplemented with $0.5 \%$ D-glucose) [49,50]. The inoculum contained $3 \times 10^{12} \mathrm{CFU} / \mathrm{ml}$ of bacteria.

\section{Animals}

Female A/J mice (4-6 weeks of age) were obtained from Jackson Labs (Bar Harbor, ME) and acclimated to their surroundings for one week prior to infection. For all inoculations, examinations, treatments and sample collections, mice were anesthetized with isoflurane (\#57319-47406, Phoenix Pharmaceutical, St. Joseph, MO). The right eyes were examined microscopically prior to infection for corneal defects and those with defects were removed from the study. The remaining mice were then randomly assigned to groups (10 mice each). Under anesthesia, six to ten scratches forming a cross-hatch pattern were made on the cornea using a 30-gauge needle taking care not to puncture the cornea. A $2.5 \mu \mathrm{L}$ inocula of $S$. aureus USA300 (7.5 $\mathrm{x} 10^{9} \mathrm{CFU}$ ) was applied to the scarified cornea, and the eyelids were manually closed twice over the cornea.

To provide analgesia, the mice were injected subcutaneously with $0.5 \mathrm{mg} / \mathrm{kg}$ of extended release Buprenorphine (kindly provided by Dr. Lisa Krugner-Higby, UW-Madison) just prior to corneal scarification. These studies adhered to the ARVO Statement for the Use of Animals in Ophthalmic and Vision Research and NIH guidelines for the use of animals in research and were approved by the University of Wisconsin-Madison IACUC.

\section{Treatment}

A $5 \mu \mathrm{L}$ drop of $0.3 \%$ Ciprofloxacin (NDC 16571-120-50, Pack Pharmaceuticals, Buffalo Grove, IL) or $1 \%$ methylcellulose in PBS (vehicle) was applied to the cornea of the infected eye, starting at 4 hours post-infection at 2 hour intervals for a total of 5 treatments per day for 4 days.

\section{Collection of eye washes and determining number of USA300} viable cells in the washes

On days 1, 2 and 3 post-infection, tear film samples were collected and the number of viable cells of S. aureus USA300 was determined. The infected corneas were flushed with $10 \mu \mathrm{L}$ of PBS and the wash was then added to $40 \mu \mathrm{L}$ PBS and kept on ice until samples were serially diluted and spread on SM/2 agar plates. The plates were incubated at $37^{\circ} \mathrm{C}$ and colonies counted after a $24 \mathrm{hr}$ incubation period.

\section{Disease scoring}

On days 1 and 3 post-infection, ocular disease severity was scored as previously described, based on three disease parametersblepharitis, neovascularization, and stromal keratits [42,44,45]. Briefly, blepharitis, or swelling of the eyelid, was scored: $1+$, puffy eyelids; $2+$, puffy eyelids with some crusting; $3+$, eye swollen shut with severe crusting; and 4+, eye completely swollen shut and crusted over. Neovascularization, the growth of blood vessels into the cornea, was scored: $1+,<25 \%$ of the cornea involved; $2+, 25 \%$ to $50 \%$ corneal involvement; and $3+,>50 \%$ corneal involvement. Stromal keratitis was scored: $1+$, cloudiness, some iris detail visible; $2+$, iris detail obscured; $3+$, cornea totally opaque; and $4+$, corneal perforation.

\section{Histology}

All animals were euthanized at 3 days post-infection. The enucleated eyes were fixed in $4 \%$ paraformaldehyde, embedded in paraffin, sectioned, stained with hematoxylin and eosin (H\&E), and examined by light microscopy.

\section{Statistical analysis}

Statistical analyses were conducted using Sigma Plot 11.0 (Systat Software, Chicago, IL). At the designated time points, raw scores for each disease parameter were recorded for each mouse in a group. The mean disease scores were calculated for each group from the raw scores and analyzed for statistical significance. Mean peak disease scores (MPDS) were calculated as previously described [42]. The t-test or the Mann-Whitney Rank Sum test was used for pairwise comparisons of the average disease scores and MPDS of groups. $\mathrm{P}$-values $<0.05$ were deemed significant unless otherwise stated.

\section{Results}

Bacterial cell numbers from corneal washes varied from $9 \times 10^{5}$ to $5 \mathrm{X} 10^{6} \mathrm{CFU} / \mathrm{ml}$ at $24 \mathrm{hrs}$ post-infection (Figure 1). At 2 and 3 days post-infection, bacterial cell numbers in the untreated eyes remained in the range of $1 \times 10^{6} \mathrm{CFU} / \mathrm{ml}$, whereas bacterial cell numbers in the Ciprofloxacin-treated animals were reduced by $3-4 \log _{10}$. The differences in bacterial titer were significant on all days post-infection (Rank Sum Test, $\mathrm{p}<0.05$ ).

The scores for the severity of blepharitis, corneal neovascularization and stromal keratitis in vehicle and Ciprofloxacintreated mice are shown in Figure 2. In untreated mice, the blepharitis score was approximately 1.5 on day 1 post-infection and increased to 2.0 on day 3 post-infection (Figure 2A). Blepharitis scores for Ciprofloxacin-treated mice were approximately 0.75 on both days 1 and 3 post-infection (Figure 2A) and were significantly lower for the Ciprofloxacin-treated animals on day 3 post-infection, $\mathrm{p}<$ 0.05 (Figure 2A). Corneal neovascularization scores in the vehicletreated mice were approximately 2.2 on day 1 post-infection and decreased to approximately 1.5 on day 3 post-infection (Figure 2B). In Ciprofloxacin treated mice, neovascularization scores were 1.0

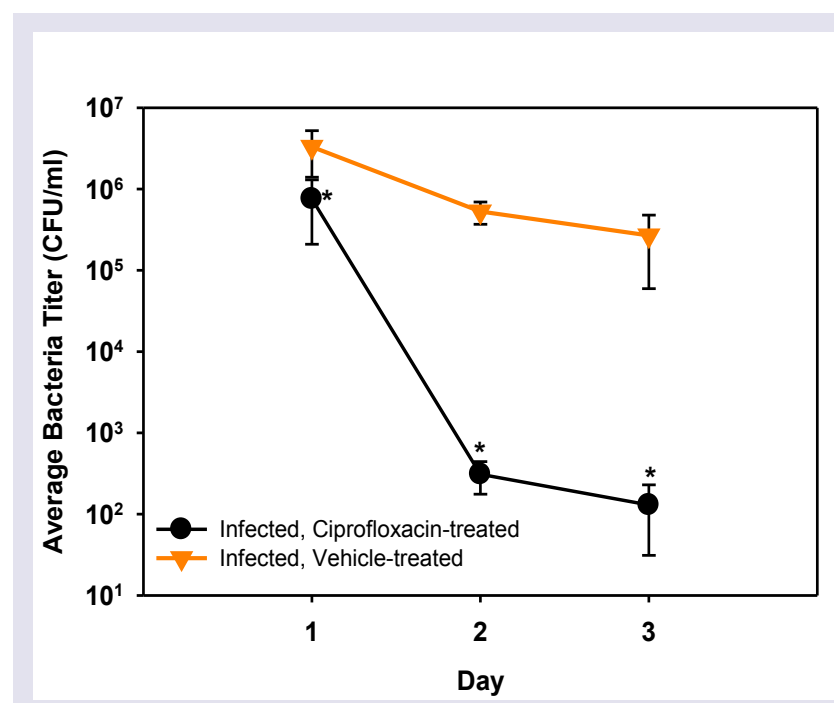

Figure 1: Bacterial titers in eye washes (CFU/ml) on days 1, 2, and 3 postinfection. All data points are the mean \pm SEM per group. ${ }^{*} p<0.05$. 


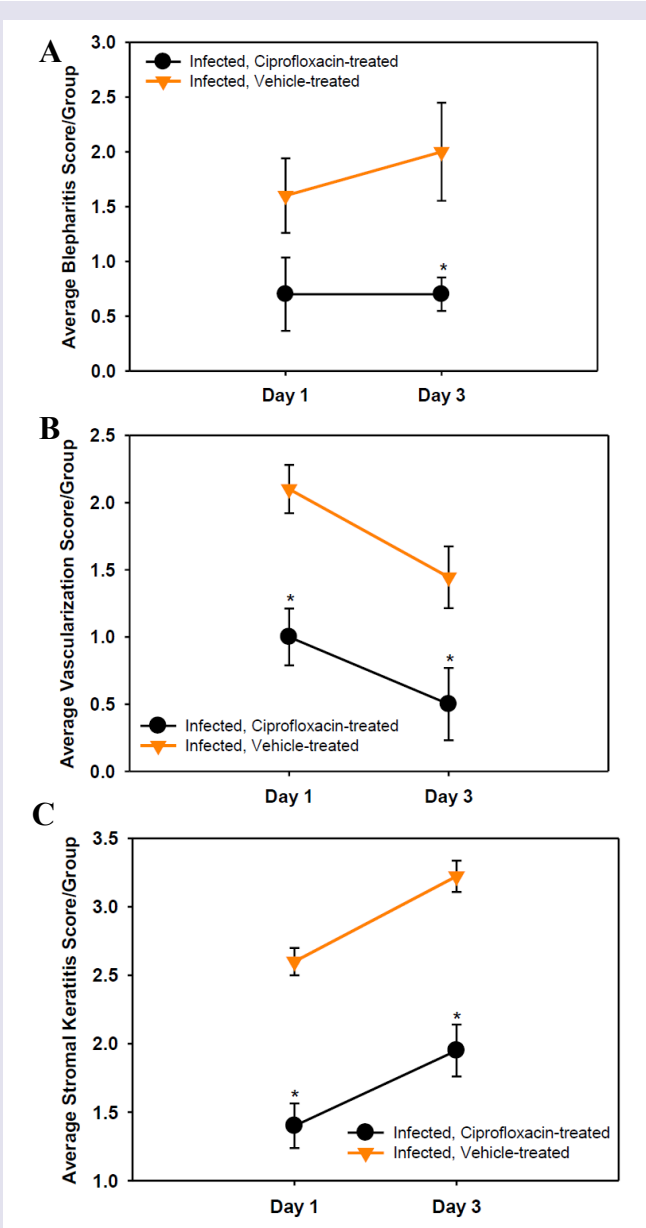

D

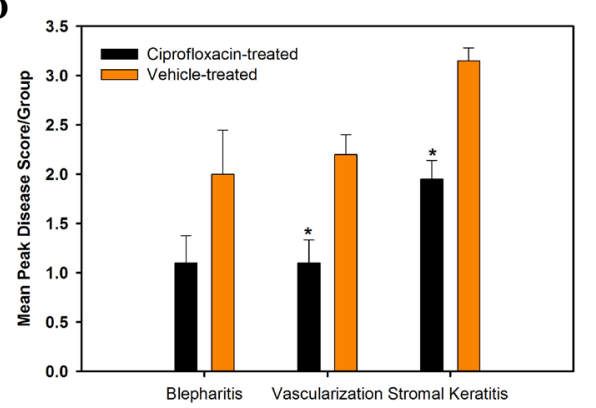

Figure 2: Ocular disease scores of Ciprofloxacin- and vehicle-treated USA300-infected mice and on 1 and 3 days post-infection. A-C represents blepharitis, vascularization, and stromal keratitis respectively. All data points represent the mean \pm SEM per group. D Mean peak disease scores (MPDS) for blepharitis, vascularization and stromal keratitis. Scores are the means of the highest scores for each mouse in a group \pm SEM. ${ }^{*} p<0.05$.

on day 1 post-infection and declined to 0.5 on day 3 post-infection (Figure 2B). Stromal keratitis scores in vehicle-treated mice were approximately 2.6 on day 1 post-infection and increased to 3.3 on day 3 post-infection (Figure 2C). In Ciprofloxacin-treated mice, stromal keratitis scores were approximately 1.4 on day 1 post-infection and increased to 2.0 on day 3 post-infection (Figure 2C). Stromal keratitis and corneal vascularization scores were significantly lower for Ciprofloxacin-treated animals on days 1 and 3 post-infection, $\mathrm{p}<0.05$ (Figures 2B and 2C). Mean peak disease scores (MPDS) are shown in
Figure 2D. For blepharitis, the MPDS were not significantly different but they were lower in the Ciprofloxacin-treated mice. For corneal vascularization and stromal keratitis, the MPDS were significantly lower for the Ciprofloxacin-treated animals, $\mathrm{p}<0.05$.

\section{Histopathology}

Eyes infected with $S$. aureus USA300 and treated with vehicle displayed marked corneal epithelial intracellular edema associated with extensive vascularization of the superficial and mid corneal stroma with moderate neutrophilic infiltration, hemorrhage and edema (Figures 3C and 3D). There was also marked hyphema and neutrophilic infiltration in the anterior chamber, especially lining the corneal endothelium and marked infiltration of neutrophils in the iris stroma associated with stromal hemorrhage and formation of a pre-iridal fibrovascular membrane. Eyes infected with $S$. aureus USA300 and treated with ciprofloxacin had mild corneal epithelial keratinization, scant neutrophils dispersed through the superficial stroma, rare neutrophils infiltrating the corneal endothelium and minimal corneal stromal edema (Figures $3 \mathrm{E}$ and $3 \mathrm{~F}$ ). All uninfected eyes present a normal microscopic appearance (Figures $3 \mathrm{~A}$ and $3 \mathrm{~B}$ ).

\section{Discussion}

S. aureus keratitis is a significant cause of blindness and the increasing percentage of drug resistant bacteria causing these infections is a major concern. Thus, there is a need for additional antibacterial agents to treat keratitis. Animal models with validated outcome measures are critical for evaluating efficacy at several stages in the drug development process. Mouse models are advantageous in early stage development because they require smaller amounts of test articles than other species commonly used, such as rabbits. Two mouse models of $S$. aureus keratitis were described previously $[33,34]$, but one of these studies used an S. aureus strain 8325-4 which is a laboratory strain that has lost the natural ability to form biofilms. Since bacterial keratitis can involve the conjunctiva and eyelids, and corneal neovascularization, these outcomes should be included in any scoring system. We therefore expanded on the previous models and used S. aureus USA300 LAC strain that forms biofilms, and have included disease scores for corneal neovascularization and blepharitis. This model should be useful for evaluating the effect of novel antibacterials on eyelid inflammation and swelling and neovascularization of the cornea.

Several studies have reported that MRSA strains are resistant to fluoroquinones, including ciprofloxacin [17,30,32,51]. For example, Freidlin et al. reported that only $14.8 \%$ of $S$. aureus isolates were susceptible to ciprofloxacin [17]. We chose to use ciprofloxacin as the positive treatment control in our study because our S. aureus USA300 strain is susceptible to the drug. However, other antibiotics could be used as controls depending on the resistance profile of the bacterial isolate being used in the model.

In summary, we have expanded on previous mouse models of $S$. aureus keratitis and included scoring of eyelid swelling and inflammation (blepharitis) and corneal neovascularization. The model should be useful for assessing additional activities of potential new antibacterial drugs, combination therapies to reduce the pathologic inflammatory response, and in studying additional pathologic mechanisms in S. aureus keratitis. 
Citation: Broekema NM, Larsen IV, Naruzawa ES, Filutowicz M, Kolb AW, et al. A Mouse Model of Multi-Drug Resistant Staphylococcus aureusinduced Ocular Disease. J Ocular Biol. 2016;4(1): 5.

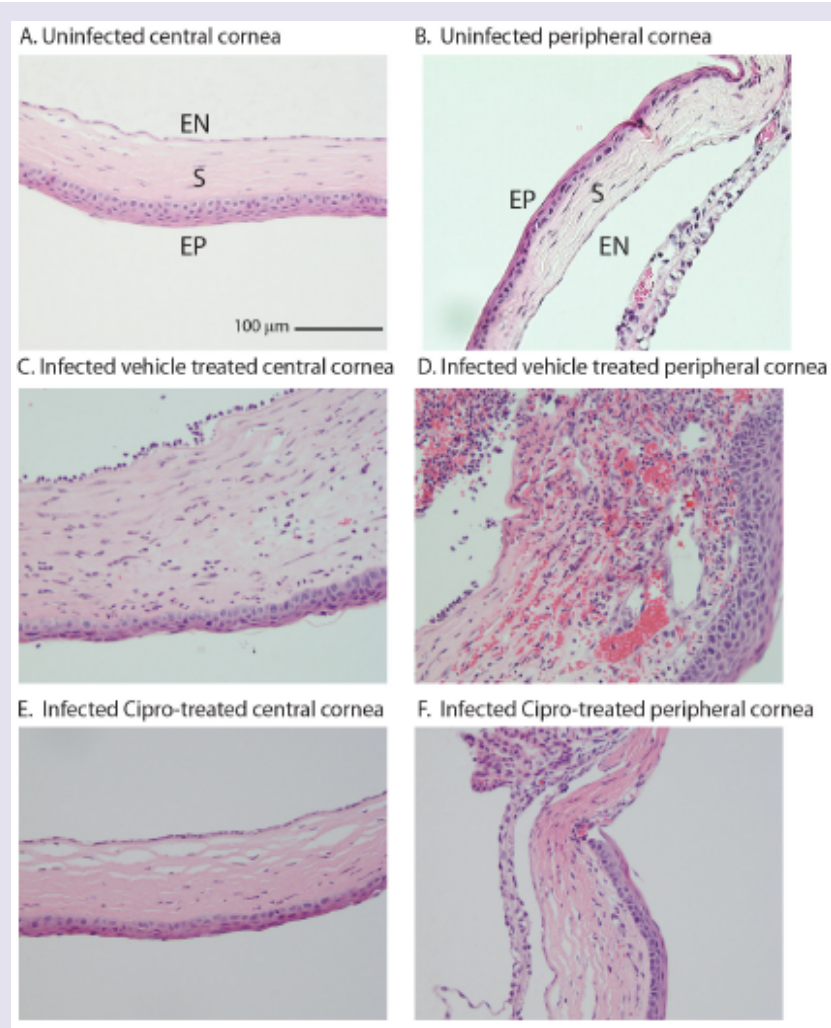

Figure 3: D Infected vehicle treated peripheral cornea. A\&B Uninfected, untreated cornea; C\&D Infected, vehicle-treated cornea; E\&F Infected, 0.3\% Ciprofloxacin-treated cornea. H\&E, Scale bar $100 \mu \mathrm{m}$. EN- corneal endothelium, S - corneal stroma; EP - corneal epithelium.

\section{References}

1. Tacconelli E, Johnson AP (2011) National guidelines for decolonization of methicillin-resistant Staphylococcus aureus carriers: the implications of recent experience in the Netherlands. J Antimicrob Chemother 66: 21952198.

2. Tacconelli E (2012) Burden of Staphylococcus aureus endocarditis: how real is the threat? Clin Microbiol Infect 18: 107-109.

3. Cookson B, Bonten MJ, Mackenzie FM, Skov RL, Verbrugh HA, et al (2011) Methicillin-resistant Staphylococcus aureus (MRSA): screening and decolonisation. Int J Antimicrob Agents 37: 195-201.

4. Lee AS, Huttner B, Harbarth S (2011) Control of methicillin-resistant Staphylococcus aureus. Infect Dis Clin North Am 25: 155-179.

5. Carey AJ, Long SS (2010) Staphylococcus aureus: a continuously evolving and formidable pathogen in the neonatal intensive care unit. Clin Perinato 37: $535-546$

6. Shinefield HR, Ruff NL (2009) Staphylococcal infections: a historical perspective. Infect Dis Clin North Am 23: 1-15.

7. Lemon KP, Klepac-Ceraj V, Schiffer HK, Brodie EL, Lynch SV, et al. (2010) Comparative analyses of the bacterial microbiota of the human nostril and oropharynx. MBio 1pii: e00129-10.

8. Chambers HF, Deleo FR (2009) Waves of resistance: Staphylococcus aureus in the antibiotic era. Nat Rev Microbiol 7: 629-641.

9. Ammerlaan HS, Kluytmans JA, Wertheim HF, Nouwen JL, Bonten MJ (2009) Eradication of methicillin-resistant Staphylococcus aureus carriage: a systematic review. Clin Infect Dis 48: 922-930.

10. Lee BY, Singh A, David MZ, Bartsch SM, Slayton RB, et al. (2013) The economic buden of community-associated methicillin-resistant Staphylococcus aureus (CA-MRSA). Clin Microbiol Infect 19: 528-536.
11. Kerr N, Stern GA (1992) Bacterial keratitis associated with vernal keratoconjunctivitis. Cornea 11: 355-359.

12. Wong VW, Lai TY, Chi SC, Lam DS (2011) Pediatric ocular surface infections: a 5-year review of demographics, clinical features, risk factors, microbiological results, and treatment. Cornea 30: 995-1002.

13. Jeng BH, Gritz DC, Kumar AB, Holsclaw DS, Porco TC, et al. (2010) Epidemiology of ulcerative keratitis in Northern California. Arch Ophthalmol 128: $1022-1028$.

14. Ong SJ, Huang YC, Tan HY, Ma DH, Lin HC, et al. (2013) Staphylococcus aureus keratitis: a review of hospital cases. PLoS One 8: e80119

15. Hsiao CH, Chuang CC, Tan HY, Ma DH, Lin KK, et al. (2012) Methicillinresistant Staphylococcus aureus ocular infection: A 10-year hospital-based study. Ophthalmology 119: 522-527.

16. Chuang CC, Hsiao CH, Tan HY, Ma DH, Lin KK, et al. (2012) Staphylococcus aureus ocular infection: methicillin resistance, clinical features and antibiotic susceptibilities. PLoS One 8: e42437.

17. Freidlin J, Acharya N, Lietman TM, Cevallos V, Whitcher JP, et al. (2007) Spectrum of eye disease caused by methicillin-resistant Staphylococcus aureus. Am J Ophthalmol 144: 313-315

18. Mah FS, Davidson R, Holland EJ, Hovanesian J, John T, et al. (2014) Current knowledge about and recommendations for ocular methicillin-resistant Staphylococcus aureus. Cataract Refract Surg 40: 1894-1908.

19. McDougal LK, Steward CD, Killgore GE, Chaitram JM, McAllister SK, et al. (2003) Pulsed-field gel electrophoresis typing of oxacillin-resistant Staphylococcus aureus isolates from the United States: establishing a national database. J Clin Microbiol 41: 5113-5120.

20. Otter JA, French GL (2010) Molecular epidemiology of community-associated methicillin resistant Staphylococcus aureus in Europe. Lancet 10: 227-239.

21. Marquardt ME (2011) Animal models of bacterial keratitis. J Biomed Biotechnol 2011: 680642

22. Cheung J, Slomovic AR (1995) Microbial etiology and predisposing factors among patients hospitalized for corneal ulceration. Can J Ophthalmol 30: 251-255.

23. Ormerod LD, Hertzmark E, Gomez DS, Stabiner RG, Schanzlin DJ, et al. (1987) Epidemiology of microbial keratitis in southern California. A multivariate analysis. Ophthalmology 94: 1322-1333.

24. Coster DJ, Badenoch PR (1987) Host, microbial, and pharmacological factors affecting the outcome of suppurative keratitis. $\mathrm{Br} \mathrm{J}$ Ophthalmol 71: 96-101.

25. Marquardt ME, O'Callaghan RJ (2013) Infectious keratitis: secreted bacterial proteins that mediate corneal damage. J Ophthalmol 2013: 369094

26. Balaban N, Novick RP (1995) Autocrine regulation of toxin synthesis by Staphylococcus aureus. Proc Natl Acad Sci U S A 92: 1619-1623.

27. D'Costa VM, McGrann KM, Hughes DW, Wright GD (2006) Sampling the antibiotic resistome. Science 311: 374-377

28. Mazel D, Davies J (1999) Antibiotic resistance in microbes. Cell Mol Life Sci 56: $742-754$.

29. Davies J (2008) Resistance redux. Infectious diseases, antibiotic resistance and the future of mankind. EMBO Rep 9 Suppl 1: S18-S21.

30. Chang VS, Dhaliwal DP, Raju L, Kowalski RP (2015) Antibiotic resistance in the treatment of Staphylococcus aureus keratitis: a 20 year review. Cornea 34: 698-703.

31. Sato K (2015) External ocular infections due to methicillin-resistan Staphylococcus aureus and medical history. Can J Ophthalmol 50: e97-e99.

32. Wilcox MD (2011) Review of resistance of ocular isolates of Pseudomonas aueruginosa and staphylococci from keratitis to ciprofloxacin, gentamicin and cephalosporins. Clin Exp Optom 94: 161-168.

33. Girgis DO, Sloop GD, Reed JM, O'Callaghan RJ (2003) A new topical model of Staphylococcus corneal infection in the mouse. Invest Ophthalmol Vis Sci 44: 1591-1597. 
Citation: Broekema NM, Larsen IV, Naruzawa ES, Filutowicz M, Kolb AW, et al. A Mouse Model of Multi-Drug Resistant Staphylococcus aureusinduced Ocular Disease. J Ocular Biol. 2016;4(1): 5.

ISSN: 2334-2838

34. Zaidi T, Zaidi T, Yoong P, Pier GB (2013) Staphylococcus aureus corneal infections: effect of the panton-valentine leukocidin (PVL) and antibody to PVL on virulence and pathology. Invest Ophthalmol Vis Sci 54: 4430-4438.

35. O'Neill AJ (2010) Staphylococcus aureus SH1000 and 8325-4: comparative genome sequences of key laboratory strains in staphylococcal research. Let Appl Microbiol 51: 358-361.

36. Bæk KT, Frees D, Renzoni A, Barras C, Rodriguez N, et al. (2013) Genetic variation in the Staphylococcus aureus 8325 strain lineage revealed by whole-genome sequencing PLoS One 8: e77122.

37. Cramton SE, Gerke C, Schnell NF, Nichols WW, Gotz F (1999) The intercellular adhesion (ica) locus is present in Staphylococcus aureus and is required for biofilm formation. Infect Immun 67: 5427-5433.

38. Cue D, Lei MG, Luong TT, Kuechenmeister L, Dunman PM, et al. (2009) Rbf promotes biofilm formation by Staphylococcus aureus via repression of icaR a negative regulator of icaADBC. J Bacteriol 191: 6363-6373.

39. Gotz F (2002) Staphylococcus and biofilms. Mol Microbiol 43: 1367-1378.

40. Pozzi C, Waters EM, Rudkin JK, Schaeffer CR, Lohan AJ, et al. (2012) Methicillin resistance alters the biofilm phenotype and attenuates virulence in Staphylococcus aureus device-associated infections. PLoS Pathog 8 e1002626.

41. Akkarawongsa R, Cullinan AE, Zinkel A, Clarin J, Brandt CR (2006) Cornea toxicity of cell-penetrating peptides that inhibit Herpes simplex virus entry. $J$ Ocul Pharmacol Ther 22: 279-289.

42. Brandt CR, Coakley LM, Grau DR (1992) A murine model of herpes simplex virus-induced ocular disease for antiviral drug testing. J Virol Methods 36 209-222.

43. Berdugo M, Larsen IV, Abadie C, Deloche C, Kowalczuk L, et al. (2012)
Ocular distribution, spectrum of activity, and in vivo viral neutralization of a fully humanized anti-herpes simplex virus IgG Fab fragment following topical application. Antimicrobial Agents Chemother 56: 1390-1402.

44. Brandt CR, Spencer B, Imesch P, Garneau M, Deziel R (1996) Evaluation of a peptidomimetic ribonucleotide reductase inhibitor with a murine model of herpes simplex virus type 1 ocular disease. Antimicrobial Agents Chemother 40: 1078-1084.

45. Brandt CR, Akkarawongsa R, Altmann S, Jose G, Kolb AW, et al. (2007) Evaluation of a theta-defensin in a Murine model of herpes simplex virus type 1 keratitis. Invest Ophthalmol Vis Sci 48: 5118-5124.

46. Cardozo FTGS, Larsen IV, Carballo EV, Jose G, Stern RA, et al. (2013) In vivo anti-herpes simplex virus activity of a sulfated derivative of Agaricusbrasiliensis mycelial polysaccharide. Antimicrobial Agents Chemother 57: 2541-2549.

47. Grau DR, Visalli RJ, Brandt CR (1989) Herpes simplex virus stromal keratitis is not titer-dependent and does not correlate with neurovirulence. Invest Ophthalmol Vis Sci 30: 2474-2480.

48. Jose GG, Larsen IV, Gauger JL, Carballo EV, Stern RA, et al. (2013) A cationic peptide, TAT-Cd ${ }^{0}$, inhibits herpes simplex virus type 1 ocular infection in vivo. Invest Ophthalmol Vis Sci 54: 1070-1079.

49. Fey P, Kowal AS, Gaudet P, Pilcher KE, Chisholm RL (2007) Protocols for growth and development of Dictyosteliumdiscoideum. Nat Protoc 2: 1307 1316.

50. Raper KB, Rahn AW (1984) The dictyostelids. Princeton University Press, Princeton, NJ.

51. Vola ME, Moriyama AS, Lisboa R, Vola MM, Hirai FE, et al. (2013) Prevalance and antibiotic susceptibility of methicillin-resistant Staphylococcus aureus in ocular infections. Arq Bras Oftalmol 76: 350-353.

\section{Acknowledgements}

This work was supported by NIH STTR R41EY024475-01A1 to NB and MF and CRB, a Core Grant for Vision Research NIH P30 EY016665 to $\mathrm{CRB}$, and an unrestricted grant to the Department of Ophthalmology and Visual Sciences from Research to Prevent Blindness, Inc. This work was also supported by the State Economic Engagement and Development (SEED) Research Program101-PRJ89MN awarded to MF. We thank Dr. Richard Proctor for providing strain MRSA USA300 LAC and numerous discussions. We also thank Rachel Kravitz who was interim $\mathrm{PI}$ on this project. 